\title{
Importance of vaccines in children with Down syndrome
}

\author{
Mohanned Alrahili ${ }^{1 *}$, Ali Binyamen ${ }^{2}$, Fares Al Otaibi ${ }^{3}$, Abeer Abu Alnour ${ }^{3}$, Majd Alsaadi ${ }^{3}$, \\ Shahad Aloufi ${ }^{4}$, Fatima Al Sadiq ${ }^{5}$, Wejdan Alzahrani ${ }^{6}$, Moath Aljabri ${ }^{7}$, Ahmed Alqarni ${ }^{8}$
}

${ }^{1}$ College of Medicine, King Saud bin Abdulaziz University for Health Sciences, Riyadh, Saudi Arabia

${ }^{2}$ Department of Pediatric, King Abdulaziz Hospital, Jeddah, Saudi Arabia

${ }^{3}$ College of Medicine, Ibn Sina National College, Jeddah, Saudi Arabia

${ }^{4}$ Department of Medicine, Western Al-Azizia Health Care Center, Mecca, Saudi Arabia

${ }^{5}$ College of Medicine, King Khalid University, Abha, Saudi Arabia

${ }^{6}$ College of Medicine, Batterjee Medical College, Jeddah, Saudi Arabia

${ }^{7}$ College of Medicine, Almaarefa Colleges, Riyadh, Saudi Arabia

${ }^{8}$ College of Medicine, Medical University of Lublin, Poland

Received: 08 August 2018

Accepted: 13 August 2018

\section{*Correspondence:}

Dr. Mohanned Alrahili,

E-mail: pharhili@gmail.com

Copyright: () the author(s), publisher and licensee Medip Academy. This is an open-access article distributed under the terms of the Creative Commons Attribution Non-Commercial License, which permits unrestricted non-commercial use, distribution, and reproduction in any medium, provided the original work is properly cited.

\begin{abstract}
Down syndrome is the most common chromosomal disorder affecting infants. It is characterized by various morphological features and systemic manifestations. Immune system is one of the main systems affected by trisomy 21, and it dysfunction is the major etiology for the recurrent infections encountered among patients with Down syndrome. Knowledge about immune system defects had made a considerable progress in prevention of infections among those patients, and subsequently decreased the morbidity and mortality among those patients. Many vaccines were recommended to be administered to Down syndrome patients as a means of prophylaxis against potential infections. Therefore, the life expectancy of Down syndrome witnessed a dramatic improvement during the past few decades. The aim of this review article is to discuss the immune system defects in patients with Down syndrome, the types of infections they are prone to, and the vaccines necessary for prophylaxis against these infections.
\end{abstract}

Keywords: Children, Down syndrome, Immune system, Infection, Vaccines

\section{INTRODUCTION}

To date, Down syndrome is considered the most common and most studied chromosomal disorder affecting infants. It results from trisomy of the chromosome 21 leading to multiple systemic signs and symptoms. ${ }^{1}$ Down syndrome presents with common morphological characteristics such as slanting palpebral fissures, flat nasal bridge, low-set ears, protruding large tongue, short neck, short extremities, hypoplasia of the fingers, clinodactyly, hypotonia, and joint hyper-excitability. Down syndrome is one of the most causes of mental retardation among children with chromosomal abnormalities. ${ }^{2}$ Along with the morphological features, almost all internal body organs and systems are affected. Congenital heart defects, gastrointestinal anomalies, thyroid disease, immunological dysfunction, hematological abnormalities, and myeloproliferative disorders are common. ${ }^{3,4}$

Down syndrome occurs in $1 / 600$ to $1 / 900$ newborns in the United States..$^{5}$ The life expectancy of Down syndrome patients is long with a reported average of 60 years; however, it is significantly shorter than normal individuals. ${ }^{6}$ The main causes of mortality are cardiac conduction defects and recurrent infections ${ }^{7}$. Therefore, prophylaxis against infection among those patients has 
witnessed a considerable concern among the healthcare sectors as an important preventive measure for morbidity and mortality. This article will thus review the immune system dysfunction, types of infections, and necessary vaccinations for patients with Down syndrome.

\section{IMMUNE SYSTEM DYSFUNCTION IN DOWN SYNDROME}

Trisomy 21 affects different body systems including the immune system. Various mechanisms have been found to be involved in the immune dysfunction encountered among patients with Down syndrome. These mechanisms include dysfunction of both adaptive and innate immunity as it will be depicted and summarized in this section.

\section{Adaptive immunity dysfunction}

Dysfunction of the adaptive immunity among patients with Down syndrome has been extensively studied. ${ }^{8-10}$ In the past, the humoral adaptive immunity was thought to be the main type affected by trisomy 21 because the respiratory tracts were the main location of recurrent infection. ${ }^{11}$ However, different immune response types were established later on to be involved in the disorder.

\section{Reduced lymphocytic count}

Mild to moderate lymphopenia is encountered in patients with Down syndrome. ${ }^{8}$ Both $\mathrm{B}$ and $\mathrm{T}$ lymphocytes are significantly reduced in comparison to normal healthy counterparts especially during childhood. This improves over age. Furthermore, thymus gland size is reduced, and mature naïve $\mathrm{T}$ cells and subsequently reduced. ${ }^{10} \mathrm{~T}$ cell expansion does not appear during infancy among those patients. ${ }^{8,9}$ Memory T cells are not significantly reduced. B lymphocytes are significantly decreased.

\section{Disturbed function of the antibody response to antigens or immunization}

In addition to the low count of lymphocytes, the function of the remaining cells is disturbed. For instance, the antibody response to antigen exposure is suboptimal, and the neutrophil chemotaxis is affected. Immunoglobulin (Ig) $G$ was reported to be lower among children with Down syndrome when compared to normal children. ${ }^{12}$ IgG type 2 is specifically affected. ${ }^{13}$ The immune response of the formed antibodies was found to be defective when the children are exposed to immunizations. ${ }^{14,15}$ The antibody titer after exposure to various vaccines (e.g., influenza, hepatitis A and B, pertussis, and pneumococci) was reported to be lower in children with Down syndrome compared to healthy children. ${ }^{9,16}$

\section{Innate immune dysfunction}

Innate immunity is also affected in Down syndrome. Though the exact genetic mechanism has not been yet revealed, many genes were proposed to be responsible for innate immunological deficits. These genes include SOD1 and ITGB2, however, data about them are conflicting. Indirect factors such as the transcription factor RCAN1 were reported to be involved in the dysfunction of the $\mathrm{T}$ lymphocytes and neutrophilic chemotaxis. ${ }^{17-19}$

Expressions of CD18 and cell aggregation are increased in Down syndrome patients. ${ }^{20}$ Furthermore, the number and function of natural killer cells are reduced. Interleukins 2, 7, and 10 secretion is disturbed and the production of mannan-binding proteins is affected..$^{20,21}$

\section{RECURRENT INFECTIONS AMONG PATIENTS WITH DOWN SYNDROME}

Children with Down syndrome are vulnerable to recurrent infection. The most widely encountered infections are the respiratory tract infections and otitis media., ${ }^{9,22}$ Along with the immune system dysfunction, many other factors increase the risk of those children to recurrent infections. Examples of these factors include anatomical and airway abnormalities (such as macroglossia, laryngomalacia, tracheomalacia, and pulmonary hypoplasia), gastroesophageal reflux and aspiration, congenital heart disease and heart failure, the high prevalence of obstructive sleep apnea, and congenital ear anomalies. ${ }^{9,23,24}$ With advanced ages, the immune system dysfunction presents with autoimmune and myeloproliferative diseases.

The main cause of hospital admission among Down syndrome patients is respiratory tract infections representing $54 \%$ of causes. Both upper and lower respiratory tract infections occur in Down syndrome, with the highest incidence between 1 and 5 years. About $18 \%$ of patients are admitted with pneumonia, $7 \%$ with bronchiolitis, and $6 \%$ with croup. Serious lower respiratory tract infections were reported to affect about $8 \%$ of children with Down syndrome. ${ }^{12}$

The main organism responsible for severe respiratory tract infection necessitating hospital admission among children with Down syndrome is Respiratory Syncitial Virus (RSV). Respiratory Syncitial virus-induced pneumonia was reported to be significantly higher among Down syndrome children in comparison with non-Down syndrome counterparts, and the infection was found to be more severe and subsequently require longer hospital admission. $^{25}$

Furthermore, Down syndrome children who experienced episodes of RSV-bronchiolitis were more prone to develop recurrent wheezes on prospective follow-up. ${ }^{26}$ The main bacterial organisms responsible for respiratory and middle ear infections are Streptococcus pneumoniae, Moraxella catarrhalis, and Haemophilis influenza. ${ }^{27}$ Other less established organisms include Bordetella bronchiseptica. 
Not only are the Down syndrome children vulnerable to recurrent infection, but they also suffer from prolonged course of each attack of infection. Searchers reported that the mean hospital stay for Down syndrome was two or three times longer than the mean stay of non-Down syndrome children. ${ }^{28}$

\section{VACCINES FOR CHILDREN WITH DOWN SYNDROME}

Because children with Down syndrome are susceptible to recurrent and severe infection and because their immune system is defective, preventive measures are fundamental to prevent morbidity and mortality. As aforementioned, Down syndrome patients have higher prevalence of croup, bronchiolitis, and pneumonia. Furthermore, they commonly have eczema that can be aggravated by skin infections such as chickenpox. Therefore, vaccination of those children is essential. The following vaccines are important for Down syndrome.

Down syndromes should receive the regular standard vaccines of infancy and childhood. Hepatitis B virus should be given at birth, 2 months, 4 months, and 6 months of age. At 2, 4, and 6 moths, vaccines against diphtheria, pertussis, tetanus, poliomyelitis, and hemophilus influenza $b$ are recommended, with booster doses at 15 months. The triple vaccine against measles, mumps, and rubella (MMR) is given at 15 months and 23 years. Hepatitis A vaccine is given at the age of 15 months and 2 years. ${ }^{16,29}$

Table 1: Schedule of vaccines recommended for down syndrome patients.

\begin{tabular}{|c|c|}
\hline Age & Vaccines recommended \\
\hline 0 & HBV \\
\hline 2 months & $\begin{array}{l}\text { HBV, DPT, PV, H.infl., MenC, Pneum, } \\
\text { Rota }\end{array}$ \\
\hline 4 months & HBV, DPT, PV, H. infl, Pneum, Rota \\
\hline 6 months & $\begin{array}{l}\text { HBV, DPT, PV, H.infl., } \\
\text { MenC, Pneum., Rota }\end{array}$ \\
\hline 15 months & $\begin{array}{l}\text { MenC, Pneum., MMR, } \\
\text { Varicella, HAV }\end{array}$ \\
\hline 18 months & DPT, PV, HBV \\
\hline 2 years & MMR, Varicella, HAV \\
\hline 4-6 years & annually \\
\hline $9-11$ years & DPT, HPV \\
\hline 18 years & Pneum., HBV \\
\hline 23-25 years & Pneum. \\
\hline 50 years & Pneum. \\
\hline 65 years & Pneum. \\
\hline
\end{tabular}

Additional vaccines recommended for Down syndrome patients include influenza vaccines, pneumococcal vaccines booster doses, Rota virus vaccine, human papilloma virus vaccines, meningococcal vaccines, and hepatitis $\mathrm{B}$ vaccine booster. ${ }^{30}$ Because pneumococci can result in serious upper and lower respiratory tract infections and meningitis in patients with Down syndrome, it is highly recommended that they received the full regimen of prophylaxis and booster doses against these bacteria. The vaccine should be given at the age of 2 months, 4 months, 6 months and 2 years initially. Then, the booster regimen consists of four doses given at the age of 18 years, 23 years, 50 years, and 65 years, respectively. ${ }^{31}$ After the age of 6 months, all patients with Down syndrome are recommended to receive Influenza A and $B$ vaccine on annual basis to protect them not only from the upper respiratory tract infection but also from the possible lower respiratory tract complications and the associated morbidity and mortality.

Human papilloma virus vaccine is recommended to be given as early as 9 years of age, however, it can be given up to the age of 26. For children less than 5 years who did not have chickenpox infection, administration of varicella vaccine is highly recommended particularly in the presence of skin diseases or eczema that might exaggerate with the viral infection. Hepatitis $B$ vaccine given at the age of 18 years will provide a life-long immunity and is highly recommended for Down syndrome patients.

Finally, children with Down syndrome who live in groups such as residential homes, hostels, boarding schools, and supported accommodations are highly recommended to receive meningococcal vaccine due to the high risk of acquiring meningococcal meningitis among these group accommodations..$^{29,32-34}$ The schedule of vaccines recommended for Down syndrome patients are summarized in Table 1.

\section{CONCLUSION}

Children with down syndrome are highly susceptible not only to recurrent infections, but also for severe prolonged course of the infectious disease. Upper respiratory tract infection and otitis media are by far the most common encountered infections among those patients. Many mechanisms underlie recurrent infection in Down syndrome.

Defective innate and adaptive immune system is the main etiology for infection. However, other anatomical structures abnormalities such as macroglossia, pulmonary hypoplasia, and cardiac abnormalities also play a role. All children with Down syndrome are recommended to receive additional vaccines in addition to the regular vaccination schedule.

Those additional vaccines include influenza vaccines, pneumococcal vaccines booster doses, Rota virus vaccine, human papilloma virus vaccines, meningococcal vaccines, and hepatitis B vaccine booster doses.

Funding: No funding sources

Conflict of interest: None declared

Ethical approval: Not required 


\section{REFERENCES}

1. Buckley S. Precise descriptions of Down syndrome. Down Syndr Res Pract. 2008;12(2):90.

2. Hodapp RM, DesJardin JL, Ricci LA. Genetic syndromes of mental retardation: should they matter for the early interventionist? Infants Young Child. 2003;16(2):152-60.

3. Lu J, Shee V. Genetic and epigenetic mechanisms in down syndrome brain. In: Down Syndrome. InTech. 2013.

4. Stoel-Gammon C. Down syndrome phonology. Developmental patterns and intervention strategies. Down Syndr Res Pract. 2001;7(3):93-100.

5. Canfield MA, Honein MA, Yuskiv N, et al. National estimates and race/ethnic-specific variation of selected birth defects in the United States, 19992001. Birth Defects Res Part A - Clin Mol Teratol. 2006;76(11):747-56.

6. National Down Syndrome Society. Down Syndrome Facts. 2015. Available at https://www.ndss.org/about-down-syndrome/downsyndrome-facts/. Accessed 1 June 2018.

7. Uppal H, Chandran S, Potluri R. Risk factors for mortality in Down syndrome. J Intellect Disabil Res. 2015;59(9):873-81.

8. De Hingh YCM, Van Der Vossen PW, Gemen EFA. Intrinsic abnormalities of lymphocyte counts in children with Down syndrome. J Pediatr. 2005;147(6):744-7.

9. Ram G, Chinen J. Infections and immunodeficiency in Down syndrome. Clin Exp Immunol. 2011;164(1):9-16.

10. Cocchi G, Mastrocola M, Capelli M, Bastelli A, Vitali F, Corvaglia L. Immunological patterns in young children with Down syndrome: is there a temporal trend? Acta Paediatr. 2007;96(10):147982.

11. Verstegen RHJ, Kusters MAA, Gemen EFA, De Vries E. Down syndrome B-lymphocyte subpopulations, intrinsic defect or decreased Tlymphocyte help. Pediatr Res. 2010;67(5):563-9.

12. Selikowitz M. Health problems and health checks in school-aged children with Down syndrome. J Paediatr Child Health. 1992;28(5):383-6.

13. Mehta PD, Dalton AJ, Mehta SP, Percy ME, Sersen EA, Wisniewski HM. Immunoglobulin G subclasses in older persons with Down syndrome. J Neurol Sci. 1993;117(1-2):186-91.

14. Lopez V, Ochs HD, Thuline HC, Davis SD, Wedgwood RJ. Defective antibody response to bacteriophage $\varnothing \mathrm{X} 174$ in Down syndrome. J Pediatr. 1975;86(2):207-11.

15. Hawkes RA, Philbrook SC, Boughton CR. The response of institutionalized Down's syndrome subjects to enterovirus infections. J Hyg (Lond). 1980;84(3):433-41.

16. Ferreira CT, Leite JC, Taniguchi A, Vieira SM, Pereira-Lima J, da Silveira TR. Immunogenicity and safety of an inactivated hepatitis A vaccine in children with Down syndrome. J Pediatr Gastroenterol Nutr. 2004;39(4):337-40.

17. Kim YS, Cho KO, Lee HJ, Kim SY, Sato Y, Cho YJ. Down syndrome candidate region 1 increases the stability of the I $\kappa \mathrm{B} \alpha$ protein implications for its anti-inflammatory effects. J Biol Chem. 2006;281(51):39051-61.

18. Wilcock DM, Griffin WST. Down's syndrome, neuroinflammation, and Alzheimer neuropathogenesis. J Neuroinflammation. 2013;10(1):864.

19. Cuadrado E, Barrena MJ. Immune dysfunction in Down's syndrome: Primary immune deficiency or early senescence of the immune system? Clin Immunol Immunopathol. 1996;78(3):209-14.

20. Guazzarotti L, Trabattoni D, Castelletti E. T lymphocyte maturation is impaired in healthy young individuals carrying trisomy 21 (Down syndrome). Am J Intellect Dev Disabil. 2009;114(2):100-9.

21. Nisihara RM, Utiyama SRR, Oliveira NP, MessiasReason IJ. Mannan-binding lectin deficiency increases the risk of recurrent infections in children with Down's syndrome. Hum Immunol. 2010;71(1):63-6.

22. Austeng ME, Akre H, Øverland B, Abdelnoor M, Falkenberg ES, Kværner KJ. Otitis media with effusion in children with in Down syndrome. Int $\mathbf{J}$ Pediatr Otorhinolaryngol. 2013;77(8):1329-32.

23. Sheikh S, Allen E, Shell R. Chronic aspiration without gastroesophageal reflux as a cause of chronic respiratory symptoms in neurologically normal infants. Chest. 2001;120(4):1190-5.

24. Zárate N, Mearin F, Hidalgo A, Malagelada JR. Prospective evaluation of esophageal motor dysfunction in Down's syndrome. Am J Gastroenterol. 2001;96(6):1718-24.

25. Bloemers BLP, van Furth AM, Weijerman ME. Down syndrome: a novel risk factor for respiratory syncytial virus bronchiolitis--a prospective birthcohort study. Pediatr. 2007;120(4):e1076-81.

26. Megged O, Schlesinger Y. Down syndrome and respiratory syncytial virus infection. Pediatr Infect Dis J. 2010;29(7):672-3.

27. Casey JR, Pichichero ME. Changes in frequency and pathogens causing acute otitis media in 19952003. Pediatr Infect Dis J. 2004;23(9):824-8.

28. Hilton JM, Fitzgerald DA, Cooper DM. Respiratory morbidity of hospitalized children with Trisomy 21 . J Paediatr Child Health. 1999;35(4):383-6.

29. Espa D. Vaccination schedule for people with Down's syndrome, 2012. Int Med Rev Down Syndr. 2011;15(3):45-7.

30. Rauet JC. Diseases susceptible to vaccination and Down syndrome. Medical Rev Int on Down syndrome. 2008;12(2):18-24.

31. Joshi AY, Abraham RS, Snyder MR, Boyce TG. Immune evaluation and vaccine responses in Down syndrome: Evidence of immunodeficiency? Vaccine. 2011;29(31):5040-6. 
32. Volti LS, Mattina T, Mauro L. Safety and effectiveness of an acellular pertussis vaccine in subjects with Down's syndrome. Childs Nerv Syst. 1996;12(2):100-2.

33. Garibotti EJ, Cervellini PM, Piccolo MC. Planktonic microcrustaceans and limnological characteristics of two Pampean lagoons (Buenos Aires, Argentina). Limnetica. 2009;28(1):91-104.

34. Kusters MA, Jol-Van Der Zijde CM, Van Tol MJ. Impaired avidity maturation after tetanus toxoid booster in children with down syndrome. Pediatr Infect Dis J. 2011;30(4):357-9.

Cite this article as: Alrahili M, Binyamen A, Otaibi FA, Alnour A, Alsaadi M, Aloufi S, et al. Importance of vaccines in children with Down syndrome. Int $\mathrm{J}$ Contemp Pediatr 2018;5:1710-4. 